\title{
駆動要素の特性を考慮した ロボットマニピュレータの動力学解析
}

\author{
増 田隆 広* 有本卓** 宮 崎 文夫*** \\ Dynamic Analysis of Robotic Manipulator \\ Considering Driving Elements
}

\section{Takahiro MASUDA Suguru ARIMOTO Fumio MIYAZAKI}

\begin{abstract}
Most of industrial robotic manipulators are driven by servo motors through transmission mechanisms (reduction gears). This paper presents a more detailed analysis of manipulator dynamics, in which rotational effects of driving motor on dynamic characteristics of the manipulator are taken into consideration. To carry out the analysis, a new modeling technique is introduced in the treatment of reduction gears in the equation of motion. In the analysis, the motor rotor itself is regarded as one of links. The function of power transmission element, that is, a kinematic relation between the link rotational angle and the motor rotational angle is interpreted as a constraint condition. Then the constraint condition and the equation of motion are solved simultaneously. This method is applied to one type of the industrial robotic manipulators to demonstrate the strict effects of the centrifugal and Coriolis forces caused by motor rotation on the dynamic characteristics of the manipulator.
\end{abstract}

Key Words : Robot, Manipulator, Dynamics, Driving System, Transmission System

\section{1. まえがき}

多くの産業用ロボットのマニピュレータは, 減速機を 介して直流サーボモータによって駆動される. 、ーモ二 ックドライブ減速機では, モータロータの回転角速度は, リンク角速度の $50 \sim 100$ 倍に達する. 当然, このロータ の回転による遠心力・コリオリカがマニピュレータの動 特性に影響を及ぼす、しかし筆者の知るかぎり, 駆動モ ータの回転の効果を厳密に解析した文献はほとんどな $(1)$.

駆動モータの回転の効果を考慮するため, 一般的に採 られている方法は, 慣性行列の対角項に減速比を考慮し てロータ慣性モーメントのリンク慣性相当值を加えて新 たに慣性行列とみなす方法2)である. しかし，この方法

\footnotetext{
原稿受付 1990 年 1 月 29 日

* 三菱電機(株)稲沢製作所 ** 東京大学工学部

$* * *$ 大阪大学基碟工学部
}

では, ロータの慣性効果については考慮できるが，遠心 カ・コリオリカの効果は考慮されていない.

本稿では，モータロータの回転を考慮したロボットマ ニピュレータの動力学解析法を提案し, 解析例によって その効果を明らかにする. 解析を行らため, 本稿では, 伝達機構の取り扱いに工夫している. 提案した解析法は, モータロータも一つのリンクとみなし, リンクとロータ の回転角の関係, すなわち, 伝達機構の機能を拘束条件 として, これを運動方程式に付加して解く方法である.

多くのロボットマニピュレータのダイナミックスシミ ュレーションシステム ${ }^{3(-5)}$ は, 任意の構成の単一チェー ンの多自由度リンク系が取り扱えるようになっており, 慣性行列, 遠心力, コリオリカ, 重力項が計算機で自動 的に生成される. 提案した解析法は,この様なシミュレ ーションシステム中の解析プログラムを用いて容易に取 り扱い可能な方法である. 


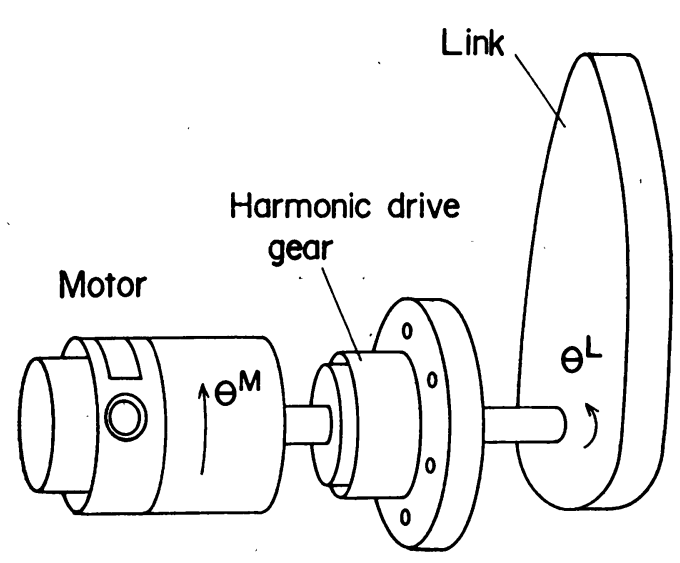

Fig. 1 Construction of a manipulator joint

\section{2. 解 析 方 法}

直流サーボモータ, 減速機, およびリンクよりなる口 ボットマニピュレータの 1 関節の構成を Fig. 1 に示す. ロータが回転した状態でのダイナミックスを取り扱うた め, ロータもリンクの一つとみなす、1関節をロータと 本来のリンクがシリーズに結合された 2 自由度のリンタ 系としてモデル化する．最初の関節がモータロータの軸 受に位置し，第 2 の関節が減速機に位置する.

因において，ロータの回転角を $\theta^{M}$, リンクの回転角 を $\theta^{L}$, 減速比を $N$ とすると, 運動学的に等価な減速機 の機能は，次式を用いてあらわすことができる.

$$
\theta^{L}=-\frac{N-1}{N} \theta^{M}
$$

ここで, 式（1.) は，ロータが $\theta^{M}$ だけ回転した時, リ ンクが $-(N-1) \theta^{M} / N$ だ回転し，べース側からみた リンクの回転角, 寸なわち, 両者の回転角の和が $\theta^{M} / \mathrm{N}$ そなることを表わしている. 式（1）は，またマニピュ レータの 1 関節を 2 自由度のリンク系でモデル化した時 の拘束条件とみなすことができる。

提案した解析法を要約すると, 以下の通りとなる.

（1）モータロータもリンクの一つとみなし，マニピ ニレータの 1 関節を 2 自由度のリンク系でモデル 化する.

（2）リンクとモータの回転角の関係，すなわち, 減 速機の機能を拘束条件とみなす。

（3）この拘束条件のもとでリンクとロータより構成 される運動方程式を解く.

本解析は，既に提案している関節空間での拘束条件付力 学系の解析尚の一つの応用と考兄ることができる。

\section{1 順ダイナミックス}

運動方程式は、マニピュレータに一般に用いられてい る次式を適用することができる．対象とするマニピュレ 一タは，回転・直動の任意の組み合せからなる単一チェ ーンの多自由度リンク系である.このような力学系につ いて, 多くの運動方程式の生成法が提案されている(2) -12).

$$
\begin{gathered}
{[W](\ddot{\theta})=\left(\tilde{p}+Y-V^{T}\right)} \\
\text { ここで, } \\
n: \text { マニピニレータの自由度 } \\
W \in R^{2 n \times 2 n}: \text { 慣性行列 } \\
\theta \in R^{2 n}: \text { 関節変位 } \\
\tilde{p} \in R^{2 n}: \text { 関節駆動トルク } \\
Y \in R^{2 n}: \text { 重力項 } \\
V \in R^{2 n}: \text { 遠心力, コリオリカ項 } \\
\text { 添字 } T: \text { 転置 } \\
\text { “.”: 時間微分 }
\end{gathered}
$$

である。

モータとリンクの回転軸・回転方向が同一とし，すべ てのモータの回転の効果を考虑する時, 式 (2) 中の変 数ベクトル $\theta$ と市の構成は次式となる.

$$
\begin{aligned}
& \theta=\left(\theta_{1}{ }^{M}, \theta_{1}{ }^{L}, \theta_{2}{ }^{M}, \theta_{2}{ }^{L}, \cdots, \theta_{n}{ }^{M}, \theta_{n}{ }^{L}\right)^{T} \\
& \tilde{p}=\left(\tilde{p}_{1}{ }^{M}, \tilde{p}_{1}{ }^{L}, \tilde{p}_{2}{ }^{M}, \tilde{p}_{2}{ }^{L}, \cdots, \tilde{p}_{n}{ }^{M}, \tilde{p}_{n}{ }^{L}\right)^{T}
\end{aligned}
$$

ここで, 後述のように式（2）中のトルクがそのまま真 のモータ駆動トルクを示していないため, 駆動トルクを 表わす变数として添字〜を付けた $\tilde{p}$ をいている. 運 動方程式 (2) の次元が $2 n$ で, これに次の $n$ 次元の 拘束条件が付加される.

$$
\theta_{i}{ }^{L}=-\frac{N_{i}-1}{N_{\imath}} \theta_{i}{ }^{M} \quad(i=1,2, \cdots, n)
$$

拘束条件を満足するための駆動トルク項にラグランジ 二乗数を導入する．後述のように，このラグランジュ乗 数は, 減速機で発生する反作用トルクに相当する.

$$
\lambda=\left(\lambda_{1}, \lambda_{2}, \cdots, \lambda_{n}\right)^{T}
$$

拘束条件の時間に関する 2 階微分を求める.

$$
\ddot{\theta}_{i}^{L}=-\frac{N_{i}-1}{N_{i}} \ddot{\theta}_{i}{ }^{M} \quad(i=1,2, \cdots, n)
$$

式 (2)，（6）および（7）を変形することにより， 次の順ダイナミックスの運動方程式が得られる.

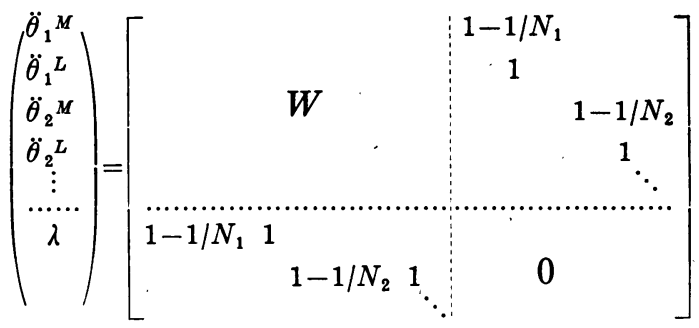




$$
\times\left(\begin{array}{c}
p_{1}{ }^{M}+Y_{1}-V_{1} \\
Y_{2}-V_{2} \\
p_{2}{ }^{M}+Y_{3}-V_{3} \\
Y_{4}-V_{4} \\
\vdots \\
\cdots \ldots \ldots \ldots . \\
0
\end{array}\right)
$$

ここで，各関節の拘束条件を表わす部分行列は，仮想仕 事の原理により，対称に配置される. 駆動トルク $p_{i}^{M}$ は，モータロータに相当する関節のみに与方，減速機に 相当する関節は 0 となる。

\section{2 逆ダイナミックス}

各リンクの運動を与える時に，ロータとリンクそれぞ れに式（1）の関保を満足するような運動を与える.

式（8）の順ダイナミックスの運動方程式を展開する と, 次の式（9）と拘束条件を表わす既出の式（7）が 得られる.

$$
\left(\begin{array}{c}
p_{1}{ }^{M} \\
p_{1}{ }^{L} \\
p_{2}{ }^{M} \\
p_{2}{ }^{L} \\
\vdots
\end{array}\right)=[W]\left(\begin{array}{c}
\ddot{\theta}_{1}{ }^{M} \\
\ddot{\theta}_{1} L \\
\ddot{\theta}_{2}{ }^{M} \\
\ddot{\theta}_{2} L \\
\vdots
\end{array}\right)
$$

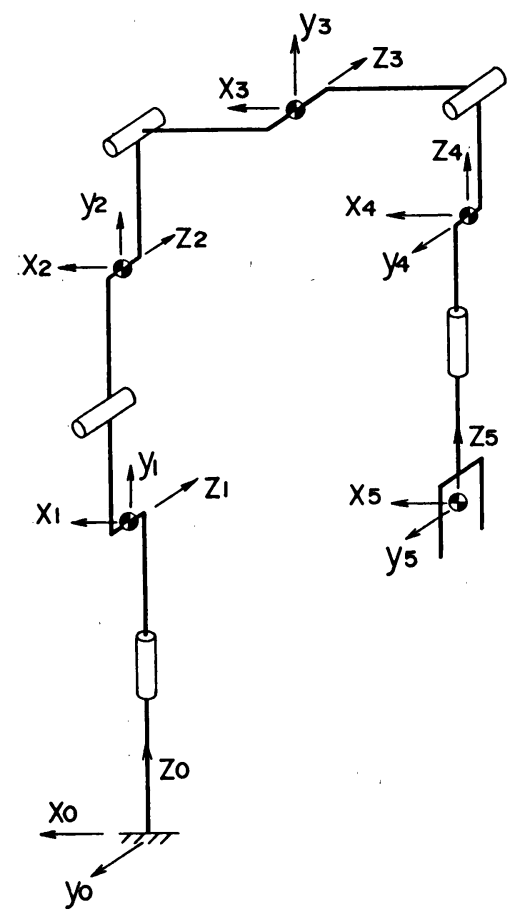

Fig. 2 Dynamical model of a 5 d. o.f. vertical articulated manipulator

$$
-\left(\begin{array}{c}
Y-V^{T} \\
\end{array}\right)+\left(\begin{array}{c}
\left(N_{1}-1\right) \lambda_{1} / N_{1} \\
\lambda_{1} \\
\left(N_{2}-1\right) \lambda_{2} / N_{2} \\
\lambda_{2} \\
\vdots
\end{array}\right)
$$

式（2）より $\tilde{p}$ を求め, 式（9）に代入することによ り次の二つの式が得られる.

$$
\begin{aligned}
& p_{t}^{M}=\tilde{p}_{i}{ }^{M}+\frac{N_{i}-1}{N_{i}} \lambda_{i} \quad(i=1,2, \cdots, n) \\
& p_{i}{ }^{L}=\tilde{p}_{i}{ }^{L}+\lambda_{i} \quad(i=1,2, \cdots, n)
\end{aligned}
$$

伝達機構自身がトルクを発生しないことから，

$$
\tilde{p}_{i}{ }^{L}+\lambda_{i}=0 \quad(i=1,2, \cdots, n)
$$

それ故, 式 (2) より求まるロータに相当する関節駆動 トルクに対し, 次式の変換を行らことにより,マニピュ レータに所定の運動をさせるためのモータトルクを求め ることができる。

$$
p_{i}{ }^{M}=\tilde{p}_{i}{ }^{M}-\frac{N_{i}-1}{N_{i}} \tilde{p}_{i}{ }^{L} \quad(i=1,2, \cdots, n)
$$

ここで， $\tilde{p}_{i}{ }^{M}, \tilde{p}_{i}{ }^{L}$ は，それぞれ式（2）の逆ダイナミッ クス計算で求をるロータとリンク部の駆動トルクであり, $p_{i}^{M}$ は, モータに実際に与えるべき駆動トルクである.

\section{3. 解 析 例}

3.1 ロータの遠心カ・コリオリカ項

本解析法を実際の産業用ロボットに適用してモータ回

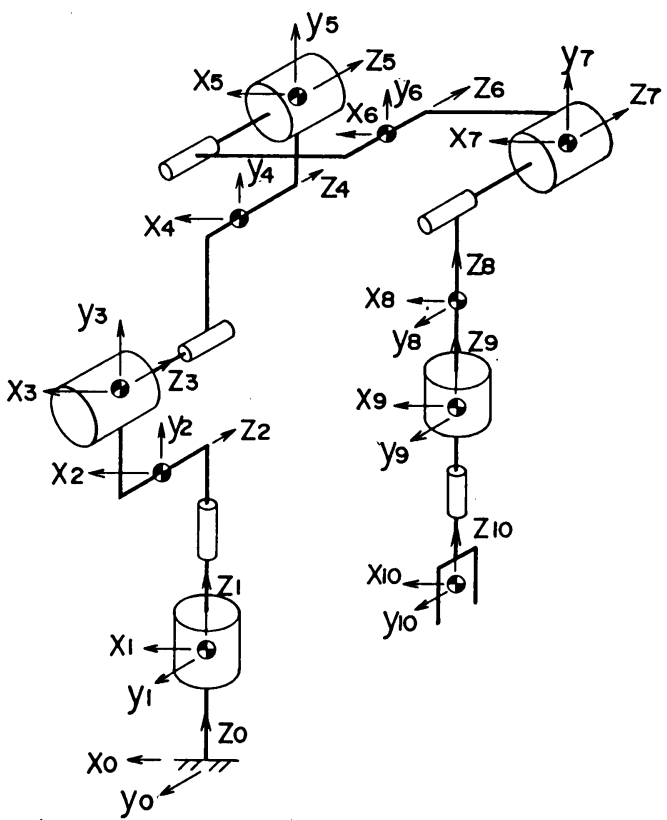

Fig. 3 Analytical model of our method (10 d.o.f.) 
転の効果を明らかにする. 解析の対象としたロボットは 5 自由度の垂直多関節形で，その力学モデルを Fig. 2 に示す. このマニピュレータに対し，モータロータの回 転の効果を明らかにするため, ロータもリンクの一つと みなした 10 自由度の力学モデルを Fig. 3 に示す. 10 自由度の力学モデルについて, マニピュレータ諸元を

Table 1，Table 2 に示す。また，これと等価な 5 自由 度の力学系, すなわち, Fig. 2 の解析モデルについてリ ンクの一端にモータロータを付加してリンク諸元を算出 した結果を Table 3, Table 4 に示す. それ故, 両解析 モデルの重力項は等しくなっている.

解析したロボットマニピュレータの運動を, 各関節の

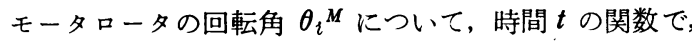
次式に示す.

$$
\left.\begin{array}{l}
\bar{\theta}_{1}{ }^{M}=\bar{\theta}_{2}{ }^{M}=(N \pi / 2)\left\{-2(t / 0.8)^{3}+3(t / 0.8)^{2}\right\} \\
\bar{\theta}_{3}{ }^{M}=\bar{\theta}_{4}{ }^{M}=(N \pi / 2)\left\{-2(t / 0.8)^{3}+3(t / 0.8)^{2}-1\right\} \\
\bar{\theta}_{5}{ }^{M}=(N \pi)\left\{-2(t / 0.8)^{3}+3(t / 5.8)^{2}\right\}
\end{array}\right\}
$$

与えた運動の初期と終端の姿勢を Fig. 4 に示す. マ二 ピュレータの関節について言えば, 0.8 秒で, 関節 $1 \sim$
4 は $\pi / 2$, 関節 5 は $\pi$ ラジアン回転する運動である.こ の運動に必要な各関節の駆動トルクを次の 3 条件につい て求めた。

（1） 5 自由度力学モデルの慣性行列のみから計算

（2） 5 自由度力学モデルの慣性行列の対角項 $W_{i \imath}$ に次式に示すように，モータロータのリンク慣性 相当値を加えた等価慣性行列から計算 $W_{i i^{\prime}}=W_{i \imath}+I_{i}{ }^{M} N_{i}^{2} \quad(i=1,2, \cdots, n) \quad$ (15) ここで， $I_{i}{ }^{M}, N_{i}$ はそれぞれ駆動モータのロータ 慣性モーメント，減速比である.

（3）本稿で提案した 10 自由度力学モデルによる厳 密な計算

上記（2），(3) の解析結果がほとんど等しく，トル クプロットでは, 両者の差異が判別困難である.このた め, Fig. 5 では, 次の三つをプロットしている.

CASE \#1：（1）と（3）の差（モータロータの慣性 項と遠心力・コリオリ力項)

CASE\#2：(2) と（3）の差モータロータの遠心 カ・コリオリカ項)

CASE \#3:（3）と（3）の差（常に0）
Table 1 Length and center of gravity (10 d. o.f.)

\begin{tabular}{|c|c|c|c|c|c|c|c|}
\hline & \multicolumn{4}{|c|}{ Center of gravity $(\mathrm{m})$} & \multicolumn{3}{|c|}{ Length $(\mathrm{m})$} \\
\hline & $x_{g}$ & $y_{g}$. & \multicolumn{2}{|c|}{$z_{g}$} & $z_{\ell}$ & $\mathrm{y}_{e}$ & $z_{\ell}$ \\
\hline Link -1 & .0 & .0 & \multicolumn{2}{|c|}{.0} & .0 & .0 & .0 \\
\hline-2 & .0014 & .1048 & \multicolumn{2}{|c|}{.0} & .0 & .136 & -.033 \\
\hline-3 & .0 & .0 & \multicolumn{2}{|c|}{.0} & .0 & .0 & .0 \\
\hline-4 & .0 & .0712 & \multicolumn{2}{|c|}{.0074} & . 0 & .250 & .015 \\
\hline-5 & .0 & .0 & \multicolumn{2}{|c|}{.0} & .0 & .0 & .0 \\
\hline-6 & -.0773 & .0 & \multicolumn{2}{|c|}{.0020} & -.016 & .0 & .040 \\
\hline-7 & .0 & .0 & \multicolumn{2}{|c|}{.0} & .0 & .0 & .0 \\
\hline-8 & .0 & .0173 & \multicolumn{2}{|c|}{.0146} & .0 & .022 & -.049 \\
\hline-9 & .0 & .0 & \multicolumn{2}{|c|}{.0} & .0 & .0 & .0 \\
\hline \multirow[t]{3}{*}{-10} & .0 & .0 & \multicolumn{2}{|c|}{-.0635} & \multicolumn{2}{|r|}{.0} & -.0635 \\
\hline & \multirow{2}{*}{$\begin{array}{l}\text { Mass } \\
\mathrm{M}(\mathrm{kg})\end{array}$} & \multicolumn{5}{|c|}{ Moment of inertia $\left(\mathrm{kg} \cdot \mathrm{m}^{2}\right)$} & $\mathrm{N}$ \\
\hline & & $I_{x x}$ & & & & $I_{z z}$ & $(-)^{\prime}$ \\
\hline Link -1 & 0.280 & $1.31 \times 1$ & & 1.31 & $10^{-5}$ & $6.53 \times 10^{-6}$ & 100 \\
\hline-2 & 5.390 & .0378 & & .0 & & .0179 & - \\
\hline-3 & 0.280 & $1.31 \times 1$ & & 1.31 & $10^{-5}$ & $6.53 \times 10^{-6}$ & 100 \\
\hline-4 & 1.784 & .0194 & & & & .0205 & - \\
\hline-5 & 0.280 & $1.31 \times 1$ & & 1.31 & $10^{-5}$ & $6.53 \times 10^{-6}$ & 100 \\
\hline-6 & 1.294 & .0010 & & & & .00627 & - \\
\hline-7 & 0.093 & $6.44 \times 1$ & & 6.44 & $10^{-6}$ & $3.22 \times 10^{-6}$ & 100 \\
\hline-8 & 0.662 & .0006 & & & & .00029 & - \\
\hline-9 & 0.093 & $6.44 \times 1$ & & 6.4 & $10^{-6}$ & $3.22 \times 10^{-6}$ & 100 \\
\hline-10 & 1.774 & .0063 & & & 337 & .00265 & - \\
\hline
\end{tabular}

Table 2 Mass and moment of inertia (10 d.o.f.)
$\mathrm{N}$ : Reduction ratio 
Table 3 Length and center of gravity (5 d. o.f.)

Table 4 Mass and moment of inertia (5 d. o.f.)

\begin{tabular}{r|c|c|c|c|c|c}
\hline & \multicolumn{2}{|c|}{ Center of gravity $(\mathrm{m})$} & \multicolumn{4}{c}{ Length $(\mathrm{m})$} \\
& $\mathrm{x} g$ & $\mathrm{y} g$ & $\mathrm{z}_{\mathrm{g}}$ & $\mathrm{z}_{\ell}$ & $\mathrm{y}_{\ell}$ & $\mathrm{z}_{\ell}$ \\
\hline Link-1 & .00133 & .0996 & .0 & .0 & .136 & -.033 \\
-2 & .0 & .0615 & .0064 & .0 & .250 & .015 \\
-3 & -.0636 & .0 & .0164 & -.016 & .0 & .040 \\
-4 & .0 & .0152 & -.0128 & .0 & .022 & -.049 \\
-5 & .0 & .0 & -.0603 & .0 & .0 & -.0635 \\
\hline & & \multicolumn{5}{|c|}{ Moment } \\
\hline
\end{tabular}

Fig. 5 より，ロータの回転による遠心力・コリオリカ 項は慣性項の $3 \sim 5 \%$ 程度で, かなり小さく, 従来の慣 性行列の対角項にロータの等価慣性モーメントを加える 解析法は妥当であることがわかる.

\section{2 ロータ偏心の効果}

各関節のモータロータ重心に Fig. 6 に示すように $0.05 \mathrm{~mm}$ の偏心を与之, 前節と同様の解析を行った結 果を Fig. 7 に示す. 与えた偏心量は, ロータのアンバ ランスや軸受のがたに起因するもので, 通常の産業用口 ボットに存在する值である. 図よりロータ偏心によるト ルク変動は全トルク变化のほぼ $10 \%$ に達することがわ かる.

\section{4. を め}

駆動モータの動特性を厳密に考虑し得るロボットマニ ピュレータの動力学解析法を提案した. 本方法を実際の 産業用ロボットに適用して、マニピュレータの動特性に 及ぼすモータロータの回転の効果を算出した。得られた 結論は, 以下の通りである.

（1）ロータの回転による遠心力・コリオリ力項は, 慣性項の $3 \sim 5 \%$ 程度で, かなり小さく, 従来の 慣性行列の対角項にロータの等価慣性モーメント を加える解析法は妥当である.

（2）ロータ偏心によるトルク変動は，全トルク変化

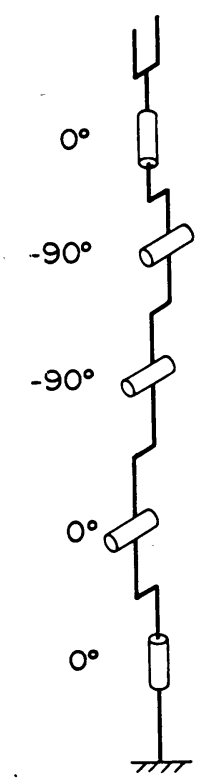

Fig. 4 Manipulator movement for numerical example
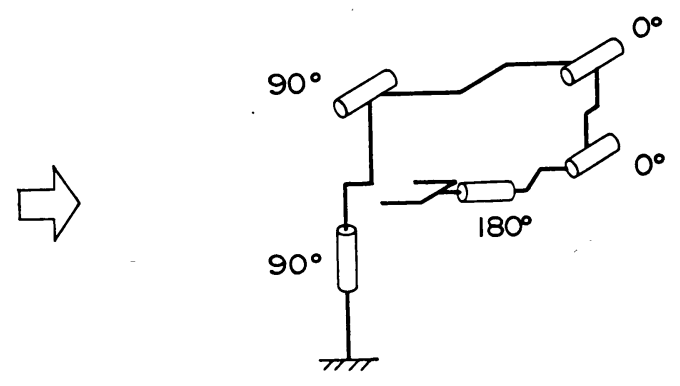

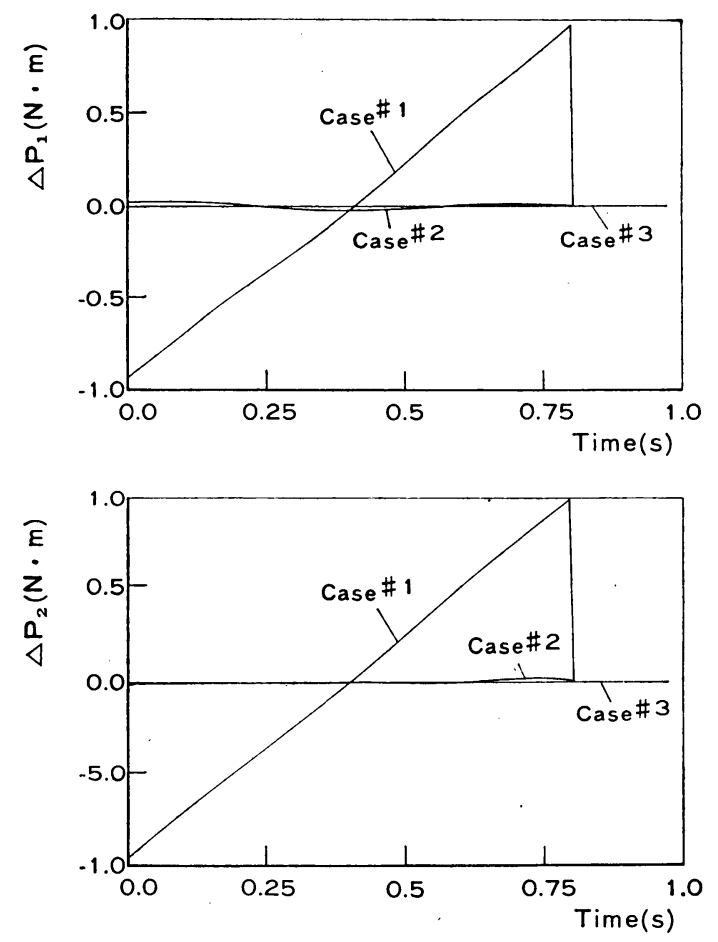

Fig. 5 Difference of driving torques

のほぼ 10\% に達する.

\section{参支献}

1) H. Springer et al., "Equation of Motion for Manipulators Including Dynamic Effects of Active Mechanism", IFAC Robot Control, pp. 425-430, 1985.

2) R.P. Paul, "Robot Manipulators", Cambridge, MA : MIT Press, pp. 45-47, 1981.

3) M.W.Walker and D.E. Orin, "Efficient Dynamic Computer Simulation of Robotic Mechanisms", ASME Trans. J. Dynamic Systems, Measurement, and Cont., Vol.104, No. 3, pp. 205-211, 1982.

4) M. Takano, K. Yashima and S. Yada, "Development of Computer Simulation System of Kinematics and Dynamics of Robot", J. of Faculty of Eng. The Univ. of Tokyo, Vol 34, No.4, 1982.

5) J.Angels, O.Ma, "Dynamic Simulation of $n$-Axis Serial Robotic Manipulators Using a Natural Orthogonal Complement", The International J. of Robotic Research, Vol.7, No.5, pp. 32-47, 1988.

6) T.Masuda et al., "Analysis of Dynamical Linkage Systems with Constraint in Joint Space and its Applications", ASME PAP 87-WA/DSC-24, pp.1-

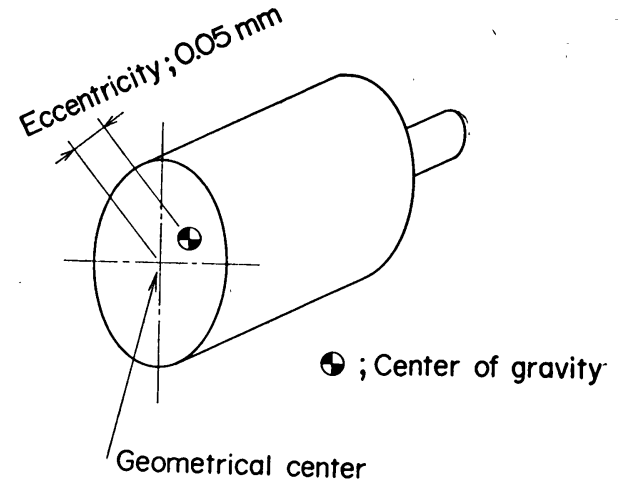

Fig. 6 Motor rotor eccentricity

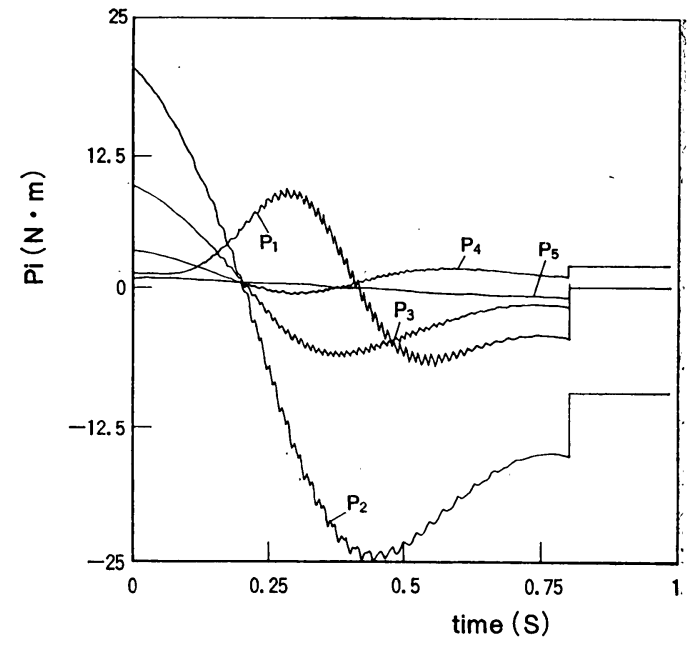

Fig. 7 Driving torques (Eccentricity $0.05 \mathrm{~mm}$ )

6, 1987.

7) J.Y.S. Luh et al., "On-Line Computational Scheme for Mechanical Manipulators", Trans. ASME, J. of Dyn. Sys. Mes. and Cont., Vol.102, No.6, pp. 69-76, 1980.

8) J. M. Hollerbach, "A Recursive Lagrangian Formulation of Manipulator Dynamics and a Comparative Study of Dynamics Formulation Complexity", IEEE Trans. Systems, Man Cybernetics, VolSMC-10, No.11, pp. 730-736, 1980.

9) M. Vukobratovic and V. Potkonjak, "Contribution of Forming of Computer Methods for Automatic Modelling of Spatial Mechanisms Motions", Mechanism and Machine Theory, Vol.14, pp.179-188, 1979.

10) R.C. Waters, "Mechanical Arm Control", MIT Artificial Intelligence Lab. Memo. 549, 1979.

11) V. Potkonjak and M. Vukobratovic, "Two New Methods for Computer Forming of Dynamic Equations of Active Mechanisms", Mech. Mach. Theory, Vol.14, No.3, pp. 189-200, 1978.

12) M. Vukobratovic and V. Potkonjak, "Scientific Fundamentals of Robotics I (Dynamics of Manipulation Robots)", Berlin : Springer, pp. 128-141, 1982. 